\title{
Benign tailgut cyst masquerading as a hemorrhoid
}

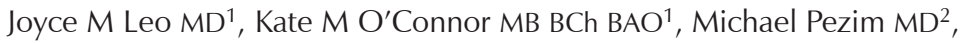 \\ Alexander Nagy $M^{3}$, David F Schaeffer MD ${ }^{1}$
}

\begin{abstract}
CASE PRESENTATION
A 79-year-old man presented with a 1.5-year history of a prolapsing cystic structure located within the anterior anal sphincter, clinically suggestive of a hemorrhoid. Physical examination demonstrated a cystic mass within the anterior anal verge, measuring up to $3 \mathrm{~cm}$ in maximum diameter. During the ensuing surgical procedure, the cystic structure was opened and contained thick purulent fluid; no solid areas were present.

The microscopic appearance (Figure 1) was of a cyst partially lined with squamous and ciliated tall columnar epithelium (short arrows) containing occasional goblet cells (long arrows); there was no evidence of dysplastic epithelial changes. Subjacent scattered bundles of fibrous connective tissue and small blood vessels were present within the cyst wall. The histological features were consistent with a benign tailgut cyst.
\end{abstract}

\section{DISCUSSION}

Tailgut cysts are cystic hamartomas that occur most commonly in the retrorectal space (also known as retrorectal cystic hamartoma) and may uncommonly occur, such as in this case, in the prerectal space (1). They are believed to develop due to failed regression of the hindgut tail during early embryonic development (2). Clinical presentation is often nonspecific, ranging from asymptomatic to local obstructive symptoms, pain or recurrent draining sinuses, fistulas or abscesses in adulthood (3). There is a female predominance (female to male ratio 3:1) with a wide age range of four to 73 years, and an average age of 35 years (2). Macroscopically, tailgut cysts range in size from $1 \mathrm{~cm}$ to $22 \mathrm{~cm}$, and may contain keratinous or amorphous debris, mucinous material or appear empty (4). Microscopically, the cysts are often lined with varying combinations of mucin-producing columnar epithelium, ciliated columnar epithelium with scattered goblet cells, transitional epithelium and squamous epithelium (2).

Differential diagnoses for a tailgut cyst include teratomas, epidermal cysts, rectal duplication cysts and anal gland cysts. Teratomas are usually lined entirely by squamous epithelium and have dermal appendages; epidermal cysts are also lined with squamous epithelium but do not have dermal appendages or smooth muscle within the wall. Rectal duplication cysts have two continuous layers of smooth muscle, unlike the focal, disorganized smooth muscle in the wall of a tailgut cyst. Anal gland cysts are differentiated from tailgut cysts primarily by their anatomical location, occurring in the prerectal space and also by their relationship to the anal surface mucosa (1). Various imaging modalities have also been used to assist with the diagnosis, but magnetic resonance imaging appears to be the preferred modality (3).

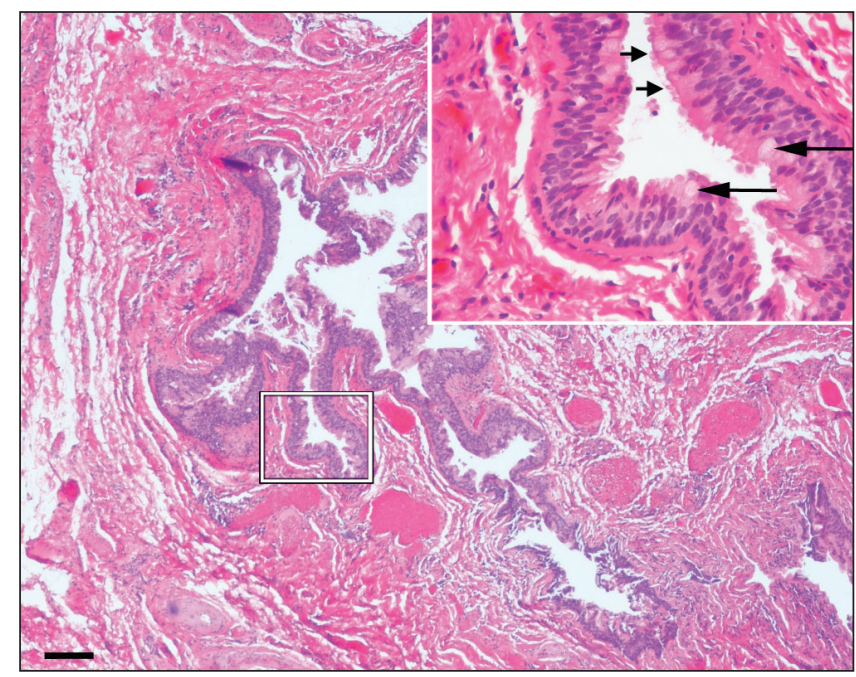

Figure 1) Microscopically, the low-power view (10x magnification) shows a cyst partially lined with squamous epithelium and ciliated tall columnar epithelium (short arrows) containing occasional goblet cells (long arrows). Subjacent scattered bundles of fibrous connective tissue and small blood vessels were present within the cyst wall. (Hematoxylin-eosin stain; inset: 40x magnification, scale bar $100 \mu \mathrm{m}$ )

Most patients remain asymptomatic; however, tailgut cysts can grow and cause local obstructive symptoms. Complete removal on discovery is recommended due to the possibility of recurrent sinus formation and to evaluate the entire cyst, which may rarely show malignant transformation to an adenocarcinoma, neuroendocrine tumour and, less likely, a squamous cell carcinoma $(3,5)$.

\section{REFERENCES}

1. Jang SH, Jang KS, Song YS, et al. Unusual prerectal location of a tailgut cyst: A case report. World J Gastroenterol 2006; 12:5081-3.

2. Hjermstad BM, Helwig EB. Tailgut cysts. Report of 53 cases. Am J Clin Pathol 1988;89:139-47.

3. Graadt van Roggen JF, Welvaart K, de Roos A, Offerhaus GJ, Hogendoorn PC. Adenocarcinoma arising within a tailgut cyst: Clinicopathological description and follow up of an unusual case. J Clin Pathol 1999;52:310-2.

4. Joyce EA, Kavanagh DO, Winter DC. A rare cause of low back pain: Report of a tailgut cyst. Case Rep Med 2012;12:1-4.

5. Spada F, Pelosi G, Squadroni M, et al. Neuroendocrine tumour arising inside a retro-rectal tailgut cyst: Report of two cases and a review of the literature. Ecancermdeicalscience 2011;5:201.

${ }^{1}$ Division of Anatomic Pathology, Vancouver General Hospital, Department of Pathology $\mathscr{E}$ Laboratory Medicine, University of British Columbia;

${ }^{2}$ Pezim Clinic; ${ }^{3}$ Department of Surgery, Vancouver General Hospital, University of British Columbia, Vancouver, British Columbia

Correspondence: Dr Joyce M Leo, Division of Anatomic Pathology, Vancouver General Hospital, 910 West 10th Avenue, Vancouver, British Columbia V5Z 4 E3.

Telephone 604-875-4480, fax 604-875-4797, e-mail joyce.leo@alumni.ubc.ca

Received for publication January 28, 2014. Accepted Febraury 7, 2014 


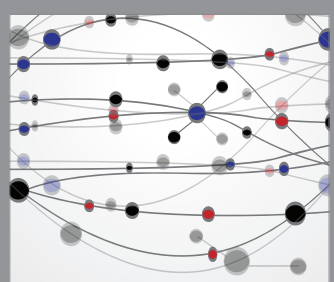

The Scientific World Journal
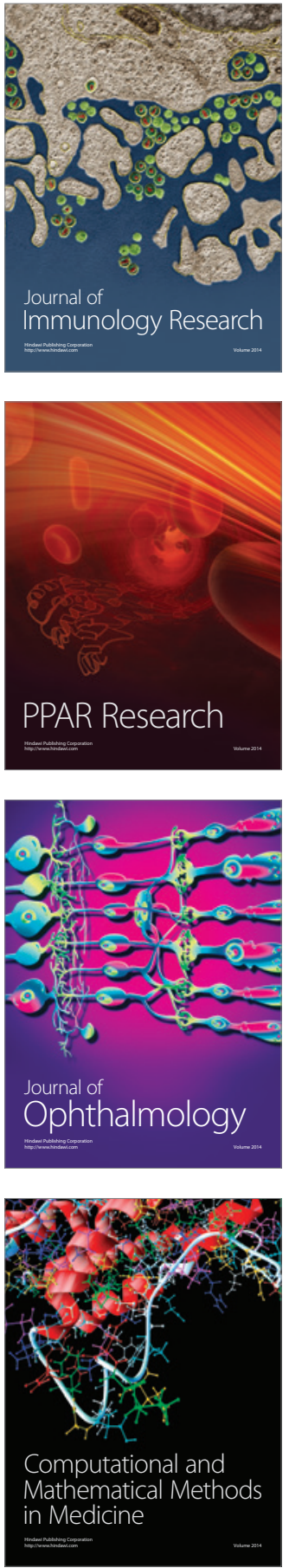

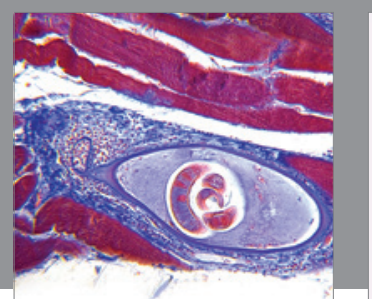

Gastroenterology Research and Practice

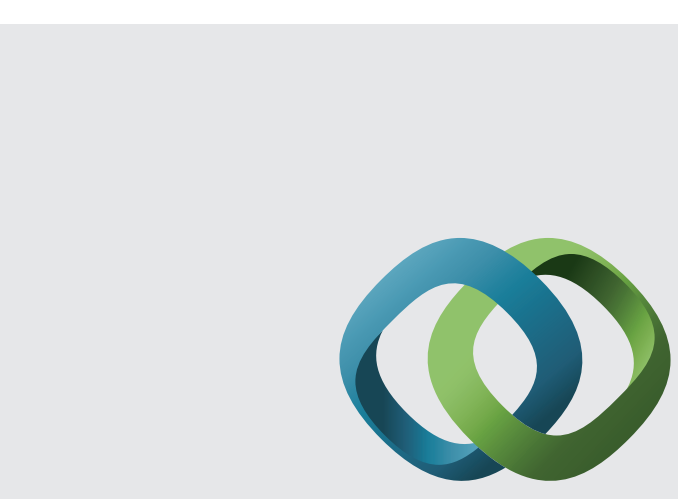

\section{Hindawi}

Submit your manuscripts at

http://www.hindawi.com
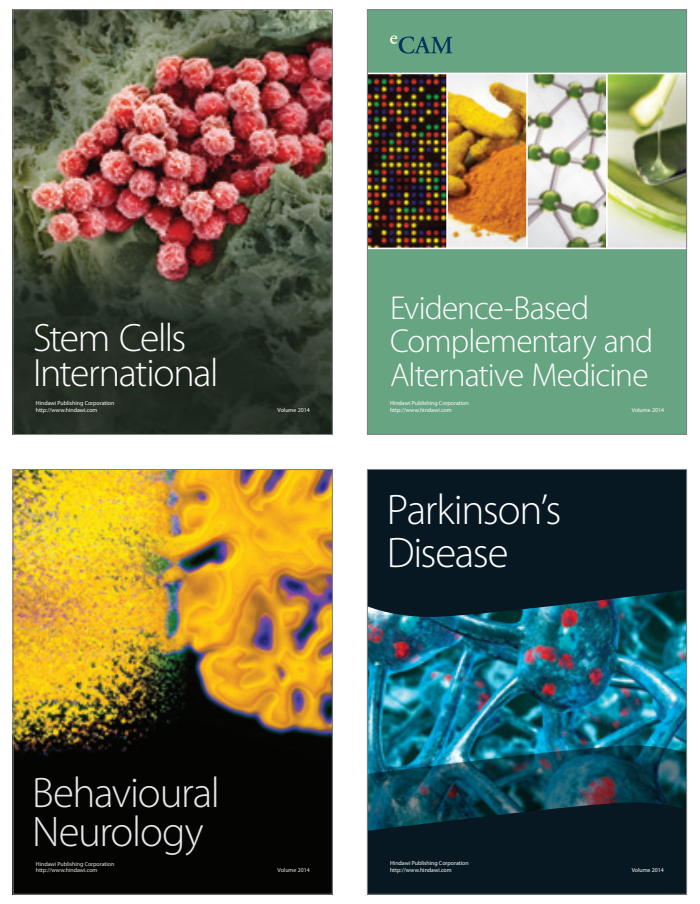
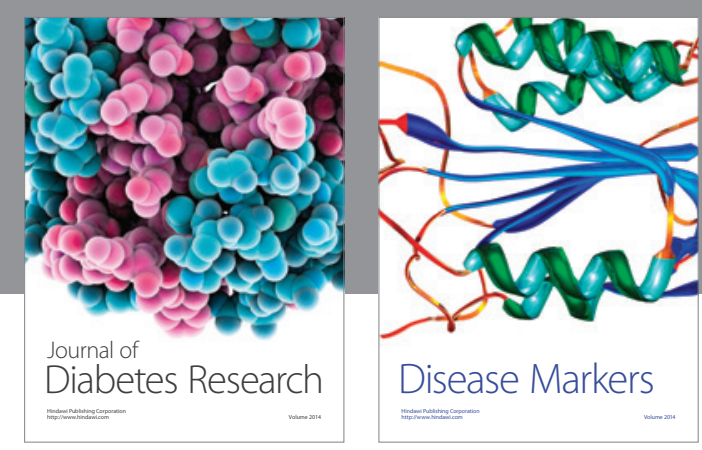

Disease Markers
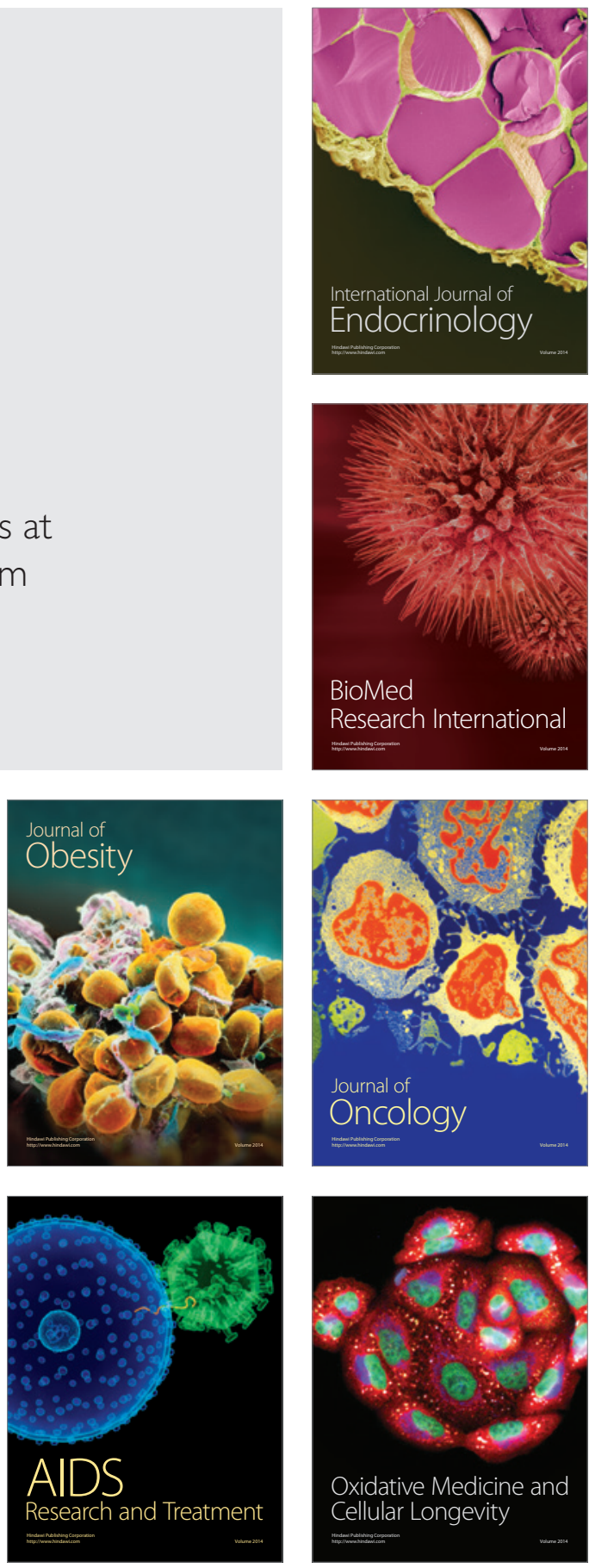